\title{
Effects of Chlorpromazine in Patients with Hepatic Disease
}

\author{
A. E. READ,* M.D., F.R.C.P. ; J. LAIDLAW, $§$ M.B., F.R.C.P.ED. ; C. F. MCCARTHY, $\ddagger$ M.D., M.R.C.P., M.R.C.P.I.
}

British Medical fournal, 1969, 3, 497-499

\begin{abstract}
Summary : Patients with cirrhosis were found to be extremely sensitive to chlorpromazine as shown by slowing of the electroencephalograph (E.E.G.), which was particularly definite in those who had had hepatic encephalopathy previously. Patients showing the most definite E.E.G. changes were in general very sleepy and took some hours to recover after taking chlorpromazine. It is concluded that phenothiazine drugs should be used very cautiously in patients with alcoholic liver disease.
\end{abstract}

\section{Introduction}

Some patients with hepatic disease are apt to develop bouts of confusion and stupor (hepatic delirium) under certain fairly well defined circumstances. These include alimentary haemorrhage, infection, paracentesis abdominis, and the administration of drugs, among which diuretics (Read et al., 1959) and powerful sedatives (Laidlaw et al., 1961) are the most important. The way in which sedative drugs produce this effect is unknown. It may be non-specific and related to an increased sensitivity of the patient with disturbed brain function to sedative drugs in general, or to the slower metabolism of the drug by a damaged liver. The tranquillizing drug chlorpromazine (Largactil) is used extensively and often in large doses in patients with alcoholic disease of the liver with accompanying neuropsychiatric syndromes. It seemed justifiable, therefore, to determine the effects of this drug in patients with liver disease, particularly where this is accompanied by bouts of hepatic delirium, and also to investigate its metabolism as well as its effects on brain function.

\section{Present Investigation}

Patients Studied.-Thirty-three volunteer control subjects without liver disease were studied, as were 29 patients with hepatic cirrhosis. The diagnosis of hepatic cirrhosis had been established in each case by liver biopsy. In 28 patients the cause of the cirrhosis was unknown, and in only one of them was it associated with alcoholism. In 14 patients there had been previous episodes of hepatic delirium. Chlorpromazine was administered in a dose of $1 \mathrm{mg}$. $/ \mathrm{kg}$. body weight, given orally as a syrup, and the effects on the electroencephalogram (E.E.G.) were investigated. All patients gave informed comment for these studies.

E.E.G. Methods.-Eight 15-second periods were recorded from the posterior aspect of the non-dominant hemisphere of each subject before and one hour after the dose of chlorpromazine. The records were fed into a modified Burden Neurological Institute wave-form analyser and a frequency distribution pattern of the rhythmic activities between 1 and 12 c.p.s. was plotted. The frequency showing the most rhythmic activity was designated the peak frequency. Each of the abundances at the various frequencies was expressed as a percentage of the total abundance of the whole record. From

\footnotetext{
* Professor of Medicine.

+ Research Fellow.

$¥$ Lecturer and Physician.

$\S$ Present appointment: Senior Physician, Chalfont Colony, Chalfont St. Peter, Bucks.

Department of Medicine, University of Bristol, Bristol BS2 8HW.
}

this the mean dominant frequency was calculated, and by sub. traction the difference between the two mean dominant frequencies, before and after the drug-a measure of the E.E.G. shift resulting from its administration. In six patients the effects of two identical doses of chlorpromazine on the E.E.G. were determined before and three weeks after a portacaval shunt, and in one patient the effect of various protein intakes on the E.E.G. change due to chlorpromazine was also measured.

Blood Ammonia.-In three patients with cirrhosis and three control subjects the fasting arterial blood ammonia was determined before and 45 minutes after the administration of the drug. Blood ammonia was measured in arterial specimens by a modified method of Seligson and Hirahara (1957) in which a standard curve was constructed during each estimation. In five patients with cirrhosis and one control subject arterial blood ammonia was measured before and at 45-minute intervals up to 135 minutes after an oral dose of $3 \mathrm{~g}$. of ammonium chloride, administered in a fruit-flavoured drink. This "ammonia tolerance test" was repeated after a dose of chlorpromazine $1 \mathrm{mg} . / \mathrm{kg}$. by mouth. A further study was made of blood arterial ammonia levels after a 3-g. ammonium chloride load in one cirrhotic, twice before and twice after a single oral dose of $180 \mathrm{mg}$. of sodium amytal.

Chlorpromazine clearance from the blood was measured at timed intervals up to 10 minutes after the intravenous injection of $1 \mathrm{mg} . / \mathrm{kg}$. of the drug. The method used was that of Leach and Crimmin (1956), which depends on an acid hydrolysis step, ether extraction, and, following the addition of ferric nitrate determination by a colorimetric technique in which the optical density is read at $530 \mathrm{~m} \mu$. Care was taken to exclude all drugs other than chlorpromazine from patients undergoing clearance studies. All those on whom clearance studies were performed received the chlorpromazine as a preoperative medication for elective surgery.

\section{Results}

\section{E.E.G. Before and After Oral Chlorpromazine}

Fig. 1 shows the calculated change in the mean dominant frequency for the control group and the liver disease group. It can be seen that the mean change between the two groups is significantly different, the control mean being $-0.21 \pm 0.065$ and the liver disease mean $-0.76 \pm 0.584(t=3.8, P<0.001)$. The distribution of the figures in the liver group, however, shows considerable scatter, so that the results have been recalculated with exclusion of the two patients with the greatest changes in this group. There is still a significant difference between these figures $(t=12.65, P<0.001)$. The one-hour change in E.E.G. mean frequency in two groups of patients with and without liver disease who were not given any drug was for the normals (15) mean change $+0 \cdot 13$ S.D. \pm 0.239 and for the cirrhotic patients (15) $-0 \cdot 13$ S.D. $\pm 0 \cdot 257$

The reason for the variability of the E.E.G. response in the patients with liver disease is shown in Fig. 2. Here the patients with liver disease are divided into those who have and those who have not had clinical evidence of pre-existing hepatic coma. Further, the shift of the E.E.G. mean dominant frequency has been plotted against the peak frequency of the pre-drug E.E.G. It is seen that patients with previous coma and a normal E.E.G. 
(peak frequency 8 or more c.p.s.) showed a tendency to a greater change in mean dominant frequency after the drug than those patients with previous coma and an abnormally slow E.E.G. $(<8$ c.p.s.). Five of six patients with previous coma showing a shift of E.E.G. mean dominant frequency of $>1$ c.p.s. resulting from the administration of chlorpromazine had normal predrug E.E.G.s (peak frequency of 8, 8, 9, 10, and 10 respectively).

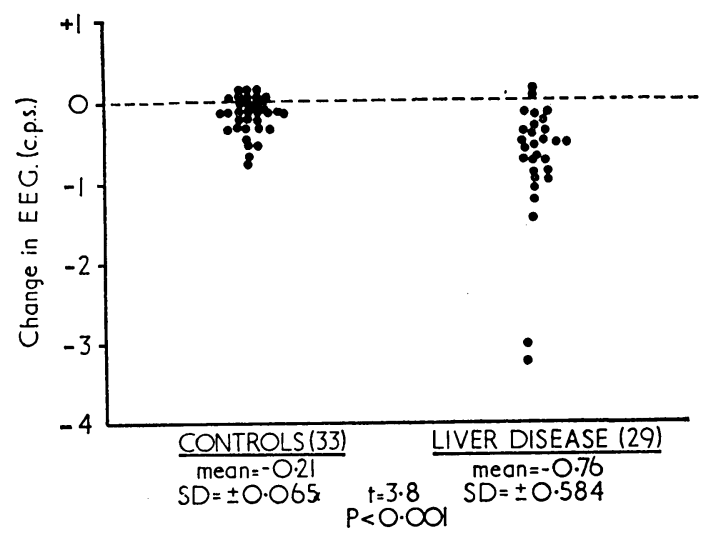

FIG. 1.-Effect of chlorpromazine on E.E.G. $(1 \mathrm{mg} . / \mathrm{kg}$. by mouth).

Patients without previous coma showed no such trend. One patient showed a minimal change in the E.E.G. mean dominant frequency between the pre-drug and post-drug records on a low protein (40 g./day) and normal protein (70 g./day) diet, whereas a large change in mean dominant frequency $(-2.7$ c.p.s.) accompanied the administration of the same dose of drug when the dieting protein intake was increased to $120 \mathrm{~g}$. daily.

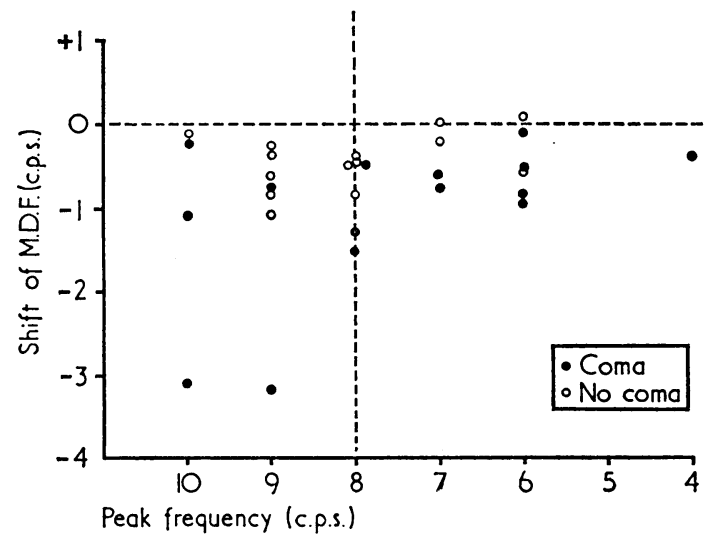

FIG. 2.-Effect of chlorpromazine on E.E.G. in liver disease (29 patients).

It was difficult to assess the degree of clinical change associated with the E.E.G. shift. In general, patients with changes of 1 c.p.s. or more were often very sleepy and took some hours to recover, whereas drowsiness was not a feature of patients with lesser E.E.G. changes.

In six patients the responses to the same oral dose of chlorpromazine before and after the operation of portacaval anastomosis were compared. In four of the six instances the change was greater after the operation, the increase ranging from -0.4 to -3.9 c.p.s. In two the preoperative and postoperative drug changes were the same.

\section{Blood Ammonia}

Blood arterial ammonia levels were not altered by the administration of chlorpromazine (Table I), but ammonia tolerance was altered by previous administration of the drug. The differences between the two ammonia tolerance tests done for each of six patients-(five cirrhotics (Cases 1-5) and one control subject (Case 6) -are shown in Table II. At zero time (basal ammonia value) the mean difference for five cirrhotics was $-0.1 \mu \mathrm{g} . / \mathrm{ml}$. (range -0.4 to +0.3 ). At 45 minutes the mean difference for five cirrhotics was $+1 \cdot 2 \mu \mathrm{g}$. (range $+3 \cdot 3$ to $-0 \cdot 1)$, and at 90 minutes the mean difference was $+1 \cdot 1 \mu \mathrm{g}$. (range +0.7 to $+1 \cdot 6$ ). On only one out of ten occasions in the five cirrhotic patients was any of the post-load differences (45 and 90 minutes) lower after chlorpromazine than before it, and here the difference was an insignificant one $(-0.1 \mu \mathrm{g} . /$ ml.). There was no significant change in the normal subject (Case 6) when changes in ammonia tolerance were determined with and without chlorpromazine.

TABLE I.-Blood Ammonia Before and After Chlorpromazine (1 mg./kg.

\begin{tabular}{c|c|c}
\multicolumn{2}{c}{ Orally $)$} \\
\hline Case No. & Before $(\mu \mathrm{g} . / \mathrm{ml})$. & 1 Hour after $(\mu \mathrm{g} . / \mathrm{ml})$. \\
\hline 1 & 0.50 & 0.37 \\
2 & 0.65 & 0.61 \\
3 & 0.31 & 0.44 \\
4 & 0.83 & 0.51 \\
5 & 0.21 & 0.52 \\
6 & 0.87 & 0.76
\end{tabular}

TABLE II.-Difference Between Ammonia Loads With and Without Chlorpromazine $(1 \mathrm{mg} . / \mathrm{kg}$. Orally)

\begin{tabular}{c|c|c|c|c}
\hline \multirow{3}{*}{ Case No. } & \multicolumn{4}{|c}{ Arterial Ammonia $(\mu \mathrm{g} . / \mathrm{ml})}$. \\
\cline { 2 - 5 } & 0 min. & $45 \mathrm{~min}$. & $90 \mathrm{~min}$. & $135 \mathrm{~min}$. \\
\hline 1 & -0.1 & +3.3 & +1.6 & +0.8 \\
2 & +0.1 & +0.1 & +1.0 & $=$ \\
3 & -0.2 & +1.0 & +0.9 & $=$ \\
4 & +0.3 & +0.9 & +0.7 & +1.3 \\
5 & -0.4 & +0.8 & -0.1 & - \\
\hline 6 & -0.2 & -0.1 & -0.1 & - \\
\hline
\end{tabular}

Only one figure is available for the time 135 minutes after $\mathrm{NH}_{4} \mathrm{Cl}$ load, and this patient (Case 1) showed a positive change $(+0.8 \mu \mathrm{g}$.) after the chlorpromazine ammonia tolerance test. In the one patient given sodium amytal twice by mouth (Table III) the ammonia tolerance test showed higher blood ammonia levels on each of two occasions after the barbiturate at the 45-minute level, but there were no significant changes at other times.

TABLE III.-Effect of Oral Barbiturate on Ammonia Load in Patient

\begin{tabular}{|c|c|c|c|c|c|c|}
\hline \multirow{2}{*}{\multicolumn{3}{|c|}{ Time }} & \multicolumn{4}{|c|}{ Arterial Ammonia ( $\mu \mathrm{g} . / \mathrm{ml})}$. \\
\hline & & & \multicolumn{2}{|c|}{ Without Barbiturate } & \multicolumn{2}{|c|}{ With Barbiturate } \\
\hline $\begin{array}{l}0 \text { min. } \\
45 \text { min. } \\
90 \text { min. } \\
135 \text { min. }\end{array}$ & $\begin{array}{l}\ldots \\
\cdots \\
\cdots\end{array}$ & $\begin{array}{l}\cdots \\
\ddot{x}\end{array}$ & $\begin{array}{l}1 \cdot 4 \\
3 \cdot 4 \\
4 \cdot 4 \\
3 \cdot 1\end{array}$ & $\begin{array}{l}1 \cdot 2 \\
3 \cdot 8 \\
4 \cdot 5 \\
3 \cdot 0\end{array}$ & $\begin{array}{l}1.5 \\
5.4 \\
4.9 \\
2 \cdot 4\end{array}$ & $\begin{array}{l}1 \cdot 4 \\
5 \cdot 3 \\
4 \cdot 1 \\
2 \cdot 3\end{array}$ \\
\hline
\end{tabular}

\section{Chlorpromazine Metabolism}

In control subjects and in cirrhotics the clearance of a standard dose of chlorpromazine from the circulation was measured over a period of 10 minutes from the injection of chlorpromazine $1 \mathrm{mg} . / \mathrm{kg}$. given intravenously. There was no apparent difference in this clearance rate, and at 10 minutes three out of four cirrhotics and two out of four controls had no detectable chlorpromazine in the blood (Table IV). In one control and one cirrhotic zero levels of chlorpromazine were reached within two minutes.

\section{Discussion}

Chlorpromazine is a sedative drug, but has little effect on the ability of the reticular formation to respond to most but not all arousal stimuli. It produces some slowing of the E.E.G. in 
the normal subject (Fink, 1959). The drug, as is the case with other phenothiazines, is well absorbed from the gastrointestinal tract, it is removed from the portal circulation by the liver, and there is a well-developed enterohepatic recirculation. After metabolic degradation or conjugation metabolites may be excreted for periods of months after the last dose. The indications for its use include delirium tremens (Small et al., 1957 ; Figurelli, 1958 ; Godfrey et al., 1958), and as a result there has been a tendency to assume that this drug is safe even in the presence of liver disease. Various disorders of basal ganglion function, particularly Parkinsonism, are known sideeffects (Ayd, 1961).

TABLB IV.-Clearance in $\mu \mathrm{g.} / \mathrm{ml}$. of Chlorpromazine After $1 \mathrm{mg.} / \mathrm{kg}$.

\begin{tabular}{|c|c|c|c|c|c|}
\hline \multicolumn{6}{|c|}{ Intr } \\
\hline Case No. & $1 \mathrm{~min}$. & $2 \mathrm{~min}$. & $3 \mathrm{~min}$. & $4 \mathrm{~min}$. & $10 \mathrm{~min}$. \\
\hline \multicolumn{6}{|c|}{ Controls } \\
\hline $\begin{array}{l}1 \\
2 \\
3 \\
4\end{array}$ & $\begin{array}{l}1.4 \\
2.8 \\
0.6 \\
5.0\end{array}$ & $\begin{array}{l}\overline{\bar{C}} \\
\overline{4} \cdot 0\end{array}$ & $\begin{array}{l}1 \cdot 2 \\
2 \cdot 0 \\
0 \\
0 \cdot 6\end{array}$ & $\begin{array}{l}\overline{\bar{c}} \\
0.1\end{array}$ & $\begin{array}{l}0.6 \\
1.7 \\
0 \\
0\end{array}$ \\
\hline \multicolumn{6}{|c|}{ Cirrhotics } \\
\hline $\begin{array}{l}1 \\
2 \\
3 \\
4\end{array}$ & $\begin{array}{l}1.1 \\
4.2 \\
3.6 \\
3.7\end{array}$ & $\begin{array}{l}\overline{\overline{0}} \\
2 \cdot 7\end{array}$ & $\begin{array}{l}0.6 \\
2.4 \\
0 \\
1.7\end{array}$ & $\begin{array}{l}\overline{-} \\
0 \\
0 \cdot 7\end{array}$ & $\begin{array}{l}0 \\
0 \cdot 6 \\
0 \\
0\end{array}$ \\
\hline
\end{tabular}

Our results suggest that patients with cirrhosis and hepatic encephalopathy are extremely sensitive to chlorpromazine as demonstrated by the E.E.G. The greatest degree of E.E.G. slowing is seen in patients who have experienced previous hepatic delirium, particularly where the "basal" E.E.G. remains relatively normal. That this E.E.G. change is somehow related to the identical changes that occur in spontaneous hepatic encephalopathy is suggested by the modifying effects of the operation of portacaval anastomosis and of a high-protein diet. Both these are circumstances under which hepatic delirium is known to be aggravated (Sherlock et al., 1954 ; Read et al., 1961). The small effect in patients with previous delirium and a slow E.E.G. is probably a compensatory one which arises as a result of the appearance of irreversible brain damage. The fact that basal ganglion dysfunction is a notable feature of hepatic delirium (Sherlock et al., 1954) accords well with the known toxic effects of chlorpromazine in non-cirrhotic subjects.

Though chlorpromazine induces a greater E.E.G. change in patients with liver disease, it does so without affecting the basal blood arterial ammonia value. The response to an oral ammonia load, however, is changed by the drug, so that the 45- and 90-minute post-load values are higher in patients who have received it. Presumably this is because of deficient removal of the administered ammonia by organs such as the liver, kidney, muscle, or brain. Measurement of arteriovenous ammonia differences across these organs might indicate the responsible $\operatorname{organ}(\mathrm{s})$. Certainly Ritchie and Shead (1962) showed a diminished removal of ammonia by the liver in dogs after an injection of morphine, and presumably chlorpromazine might have a similar effect. In any case the effect seems to be a non-specific one in that similar but less consistent alterations followed the administration of a barbiturate, though regrettably it was possible to study only one such patient ; it was thought to be unethical to study others, however revealing the results might have been.

It might be expected that in patients with liver disease the metabolism of chlorpromazine occurs at a slower rate than normal, with resultant higher serum levels. Unfortunately, because of the very slow rate of chlorpromazine "turnover," studies would have to be conducted over weeks or months to determine if any such difference existed. Our own studies were related only to disappearance rates after intravenous injection of a standard chlorpromazine dose, because the detection of chlorpromazine in systemic blood was not possible after the small oral dose that we were using for the E.E.G. studies. As indicated by blood disappearance curves there appeared to be no difference in removal of chlorpromazine from the blood by normal and cirrhotic patients.

The dosage of chlorpromazine used $(1 \mathrm{mg}$. $/ \mathrm{kg}$.) by mouth is well within the therapeutic range. The possibility that even a small dose such as this could cause a heightened degree of brain depression should be borne in mind. The effect is presumably due to increased brain sensitivity, as a deficiency in metabolism has not been demonstrated, though such a change is possible. Though the syndrome of hepatic delirium is usually distinguishable from delirium tremens this distinction may sometimes be difficult to make, and, further, these neuropsychiatric abnormalities may occur together. The administration of chlorpromazine could then either produce depression of cerebral function or, by hindering the removal of blood ammonia, bring about such functional deterioration. Certain caution, as with other sedative drugs (Laidlaw et al., 1961), seems necessary, and the assumption that, because phenothiazine drugs are beneficial for patients with neurological disorders associated with alcoholic liver disease, they are harmless in patients with neurological syndromes associated with nonalcoholic liver disease needs very careful examination.

We are grateful to Dr. J. R. Clamp and Miss M. Hendy for their help with this study.

\section{REFERENCES}

Ayd, F. J. (1961). Fournal of the American Medical Association, 175, 1054.

Figurelli, F. A. (1958), fournal of the American Medical Association, $166,747$.

Fink, M. (1959). Electroencephalography and Clinical Neurophysiology, 11, 398.

Godfrey, L. G., Kissen, M. D., and Downs, T. M. (1958). Quarterly fournal of Studies on Alcohol, 19, 118.

Laidlaw, J., Read, A. E., and Sherlock, S. (1961). Gastroenterology, 40, 389.

Leach, H., and Crimmin, W. R. C. (1956). Fournal of Clinical Pathology, 9, 164 .

Read, A. E., Laidlaw, J., Haslam, R. M., and Sherlock, S. (1959). Clinical Science, 18, 409.

Read, A. E., Laidlaw, J., and Sherlock, S. (1961). Lancet, 1, 961.

Ritchie, H. D., and Shead, G. V. (1962). Gut, 4, 89.

Seligson, D., and Hirahara, K. (1957). Fournal of Laboratory and Clinical Medicine, 49, 962

Sherlock, S., Summerskill, W. H. J., White, L. P., and Phear, E. A. (1954). Lancet, 2, 453.

Small, M. D., Longarini, A. E., and Zamcheck, N. (1957). New England fournal of Medicine, 256, 932. 